34:164-181). This child had denervation of the IX, X and XI cranial nerves, absent gag reflex, speech problem, but no complaint of headaches was recorded.

\title{
ICE CREAM HEADACHE
}

The characteristics of cold induced headaches in a group of migraine patients were compared with the usual migraine headaches and with cold induced headaches in a control population, in a study using a retrospective questionnaire at the City of London Migraine Clinic, London, England. The control patients were preclinical medical and dental student volunteers. Seventeen percent of the migraine patients and $46 \%$ of the students developed headache following palatal application or a swallow of ice cream. "Ice cream headache" was less common in migraine patients than the controls, and the pattern of the headache induced by ice cream was similar in the 2 groups. Only 2 of the 12 migraine patients who developed ice cream headache on testing experienced the headache at a similar site to their usual migraines (Bird N, MacGregor EA, Wilkinson MIP. Ice cream headache - site, duration, and relationship to migraine. Headache Jan 1992; 32:35-38). (Reprints: Dr. E. Anne MacGregor, The City of London Migraine Clinic, 22 Charterhouse Square, London EC1M 6DX, England.)

COMMENT. This study suggests that ice cream headache is common but may be less common in migraine patients than the general population. These findings are in contrast to some previous studies showing that $93 \%$ of migraine patients reported ice cream headaches compared with $31 \%$ of non headache controls (Raskin NH, Knittle SC Headache $1976 ; \underline{16}: 222-225)$.

The precipitating factors noted in 6 of 51 Nigerian children with migraine were fatigue in 3 , lack of sleep in 2 , and milk chocolate drink in 1. Ice cream was not noted as migraine precipitant in this study from Kano, Nigeria (Okogbo ME. Migraine in nigerian children: a study of 51 patients. Headache Nov 1991; 31:673-676). Haemoglobin genotype obtained in 41 cases was AA in $66 \%$ and AS in $34 \%$. The prevalence of haemoglobin AS was higher than in the general population $(25 \%)$.

\section{MYASTHENIA GRAVIS}

\section{PROGNOSIS OF MYASTHENIA GRAVIS}

The prognosis of myasthenia gravis (MG) was assessed retrospectively using life table analysis in 844 patients followed up for a mean period of 5 years in 3 neurological centers in Milan, Rome and Pavia, Italy. The patients were aged from 2 to 90 years with a mean of 45 years. The onset of symptoms peaked in the young and middle age groups, and the commonest age at onset was between 20 and 39 years. The proportion of females progressively decreased with age. Sixty-two percent of patients received 